\title{
Interactive comment on "Reanalysis
} intercomparison of potential vorticity and potential-vorticity-based diagnostics" by Luis F. \section{Millan et al.}

\section{Anonymous Referee \#2}

Received and published: 12 January 2021

The comment was uploaded in the form of a supplement:

https://acp.copernicus.org/preprints/acp-2020-1181/acp-2020-1181-RC2-

supplement.pdf

Interactive comment on Atmos. Chem. Phys. Discuss., https://doi.org/10.5194/acp-2020-1181, 2020. 